\title{
KHẢO SÁT Độ CHÍNH XÁC NGUYÊN TỐ ĐỊNH HƯớNG NGOÀI CỦA ẢNH KHI SỬ DỤNG NHIỀU TRẠM BASE
}

\author{
ĐÀO NGỌC LONG ${ }^{(1)}$, PHẠM NGỌC SƠN(2) \\ (1) Viện Khoa học Đo đạc và Bản đồ \\ ${ }^{(2)}$ Công ty TNHH MTV Trắc địa Bản đồ
}

\section{Tóm tắt:}

Sử dụng dũ liệu GNSS/IMU trong quá trình bay chụp để xác định các nguyên tố định hương ngoài của ảnh phuc vu công tác thành lập bản đồ và xây dụng cơ sở dũ liệu địa lý đã được úng dụng rộng rãi trong nhũng năm gần đây. Công nghệ này đòi hỏi phải tuân thủ nhũng điều kiện chặt chẽ: về thu dũ liệu, điều khiển máy bay, đồ hình bố trí và khoảng cách tù trạm tham chiếu mặt đất tới khu vưc cần chup ảnh. Hiện nay, hệ thống trạm Cors tại Việt nam đã được xây dụng, việc nghiên cưu sủ dụng các trạm này ứng dụng trong công tác bay chụp ảnh hàng không rất có ý nghĩa trong việc nâng cao hiệu quả công tác bay chup. Bài báo này trình bày kết quả khảo sát độ chính xác nguyên tố định hướng ngoài tù dũ liệu GNSS/IMU của máy Vexcel Ultracam XP w/a được tính tùt nhiều trạm Base.

\section{1. Đặt vấn đề}

Hệ thống máy chụp ảnh số hàng không Vexcel Ultracam XP w/a đã được Công ty TNHH MTV Trắc địa Bản đồ - Cục Bản Đồ BTTM trang bị từ cuối năm 2010. Đây là hệ thống máy chụp ảnh số được tích hợp những công nghệ hiện đại, với các phần mềm xử lý chuyên dụng, có thể thu nhận được những tấm ảnh kỹ thuật số màu thực độ phân giải cao, với nguyên tố định hướng ngoài (EO) được xác định trực tiếp từ dữ liệu GNSS/IMU trong quá trình bay chụp ảnh. Những sản phẩm này hỗ trợ rất có hiệu quả cho công nghệ đo vẽ ảnh lập thể: giảm công việc đo điểm khống chế ảnh ngoại nghiệp, rút ngắn thời gian thi công.. Tuy nhiên, để thực hiện được quá trình tổ chức bay chụp ảnh phải tuân thủ các yêu cầu rất chặt chẽ về bố trí các trạm tham chiếu mặt đất (reference station). Ở nước ta, hiện nay đã có hệ thống trạm định vị vệ tinh cố định (Cors), phân bố trên cả nước. Việc đánh giá độ chính xác nguyên tố định hướng ngoài từ dữ liệu GNSS/IMU của máy Vexcel Ultracam XP w/a được tính từ nhiều trạm tham chiếu trong công tác bay chụp ảnh là rất cần thiết.

\section{Phương pháp nghiên cứu}

Phần mềm POSPAC MMS có thể xử lý dữ liệu GNSS/IMU tính ra nguyên tố định hướng ngoài của từng tấm ảnh với độ chính xác cao (từ $0.03 \mathrm{~m}$ đến $0.3 \mathrm{~m}$ ) với điều kiện các trạm tham chiếu mặt đất cách khu vực chụp ảnh trong phạm vi từ $10 \mathrm{Km}-50 \mathrm{Km}$ với trường hợp sử dụng 1 trạm tham chiếu (chế độ Single base) và khoảng cách giữa các trạm khoảng $100 \mathrm{Km}$ với trường hợp sử dụng 4 trạm trở lên (chế độ Smart base). Trong khảo sát này chúng tôi sử dụng dữ liệu của Dự án: "Xây dưng co' sở dũ liệu nền thông tin địa hình co bản và thành lập bản đồ địa hình tỷ lẹ 1:50.000 phủ trùm các khu vực Bắc và Trung Lào".

\subsection{Dũ liệu sử dụng trong nghiên cứu}

Dữ liệu bay chụp, khống chế ảnh và các điểm trạm Base:

Dũ liệu bay chup:

Đơn vị bay chụp: Bộ Quốc phòng

Phân khu bay chụp LAO-07-14 Bắc Lào

Máy chụp ảnh: VEXCEL ULTRACAM XP W/A

Ngày nhận bài: 15/01/2020, ngày chuyển phản biện: 19/01/2020, ngày chấp nhận phản biện: 05/02/2020, ngày chấp nhận đăng: 18/02/2020 
Tiêu cự: $70.5 \mathrm{~mm}$

Tỷ lệ ảnh: 1: 83.000

Độ cao bay chụp: $5800 \mathrm{~m}$

Độ phân giải mặt đất: $50 \mathrm{~cm}$

Độ phủ dọc: $60 \%$

Độ phủ ngang: 30\%

Tổng số ảnh chụp của phân khu: 609 ảnh

Ảnh bay chụp cho thành lập bản đồ tỷ lệ 1 : 50.000 , tuy nhiên với độ phân giải mặt đất $50 \mathrm{~cm}$ và độ cao bay chụp 7300m (độ cao trung bình khu vực là $1500 \mathrm{~m}$ ) và đây cũng là trần bay cao nhất với hệ thống máy bay sử dụng cho công tác bay chụp ảnh hàng không. Độ phân giải này hoàn toàn đáp ứng cho thành lập bản đồ tỷ lệ 1 : 10.000 với khoảng cao đều đường bình độ cơ bản 5 mét.

Dũ liệu khống chế ảnh: Phân khu này bố trí thành một khối với 21 điểm khống chế ảnh mặt phẳng và độ cao, 8 điểm kiểm tra (tổng 29 điểm được sử dụng để đánh giá độ chính xác của nguyên tố định hướng ngoài của ảnh). Các điểm khống chế được đo bằng công nghệ GNSS hệ tọa độ, độ cao Cộng hòa dân chủ Nhân dân Lào. (xem hinh 1)
Các điểm trạm Base: Khu đo được bố trí 5 điểm trạm Base

Trong đó:

F48-98-5: Ký hiệu khống chế ảnh

KT21: ký hiệu điểm kiểm tra

- - - - -: tâm ảnh

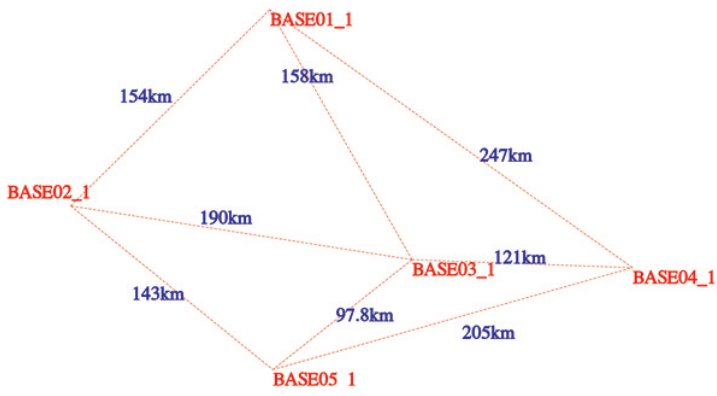

Trong đó:

Base 01-1: ký hiệu các điểm trạm Base

Hình 2: So đồ các điểm trạm Base

Khoảng cách giữa các trạm Base được thể hiện trên hình 2, khoảng cách gần nhất $97.8 \mathrm{~km}$, khoảng cách xa nhất $247 \mathrm{~km}$

\subsection{Phuơng pháp nghiên cúu}

- Sử dụng phần mềm POSPAC MMS số liệu

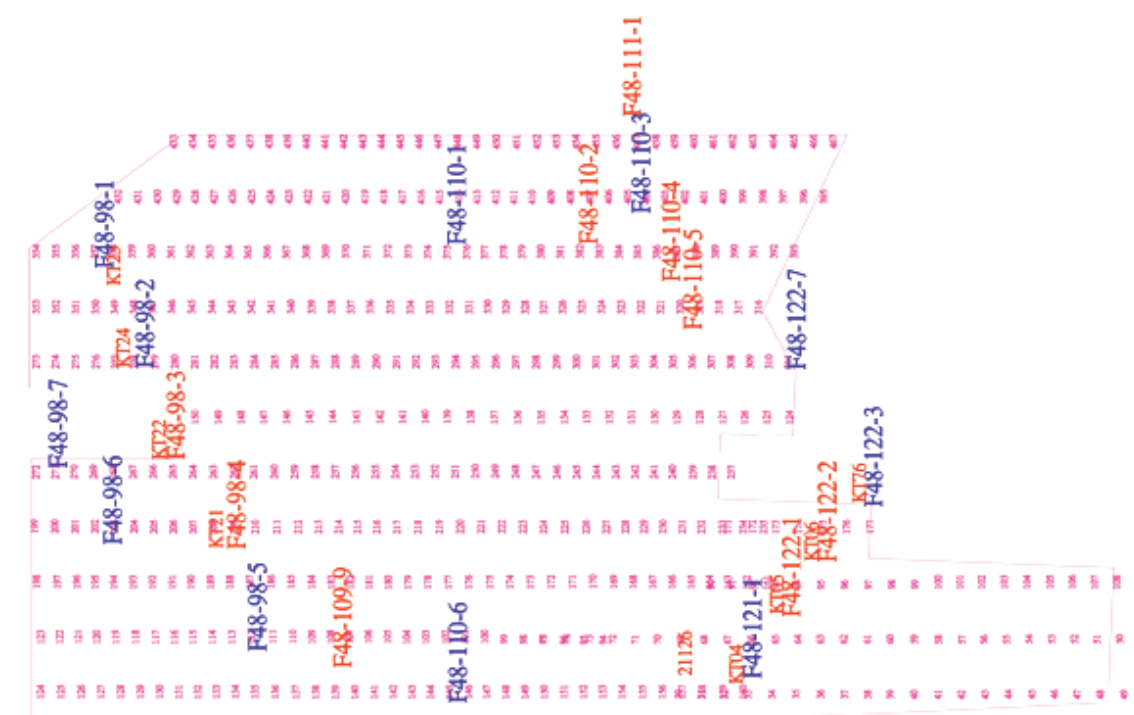

Hình 1: So đồ các điểm khống chế ảnh và các tuyến bay 
GNSS/IMU để tính giá trị EO với các phương án: từ 1 trạm Base, 4 trạm Base và 5 trạm Base.

- Số liệu đo tăng dày sử dụng kết quả từ dự án (đo bằng phần mềm khớp ảnh tự động Match $\mathrm{AT}$ trên trạm đo vẽ ảnh số Image Station)

- Tính toán bình sai tăng dày khống chế ảnh bằng phần mềm Photo-T với các phương án: chỉ sử dụng giá trị $\mathrm{EO}$ tính từ 1,4 và 5 trạm Base. Các điểm khống chế ảnh và điểm kiểm tra sử dụng để đánh giá độ chính xác.

\section{Kết quả}

Sử dụng phần mềm Photo-T tính bình sai khối ảnh với phương án chỉ sử dụng giá trị nguyên tố định hướng ngoài của ảnh được tính từ 1 trạm Base, 4 trạm Base và 5 trạm Base.

Kết quả được thống kê những thông số cơ bản của kết quả bình sai tăng dày khống chế ảnh: sai số trung phương điểm khống chế, sai số trung phương điểm kiểm tra, sai số trung phương trọng số đơn vị của ảnh (Sigma), số lần lặp, số lượng ảnh, số lượng điểm khống chế, điểm kiểm tra và được trình bày trong bảng sau: (Xem bảng 1)

Biểu đồ thể hiện sai số $\mathrm{Mx}, \mathrm{My}$ và $\mathrm{Mz}$ của các phương án tính được thể hiện trên hình vẽ sau:

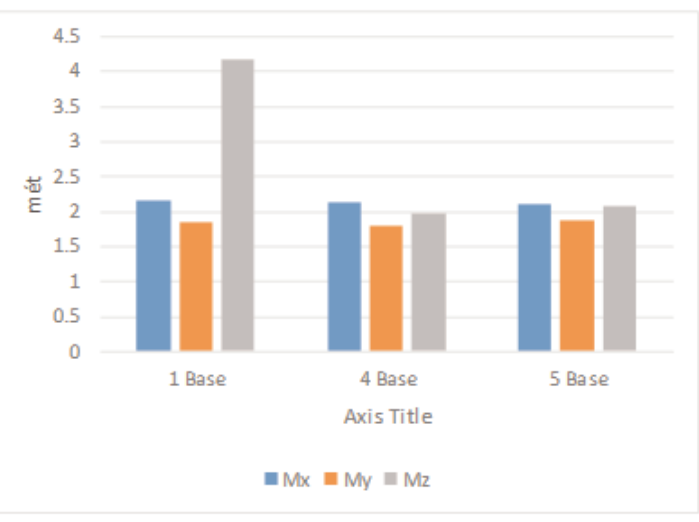

Hình 3: Biểu đồ sai số tại các điểm kiểm tra với $E O$ tính tù 1, 4 và 5 trạm Base

\section{Kết luận}

Qua số liệu trên đây, có thể đưa ra một số kết luận như sau:

Bảng 1: Tổng hợp kết quả tính toán bình sai tăng dày khống chế ảnh

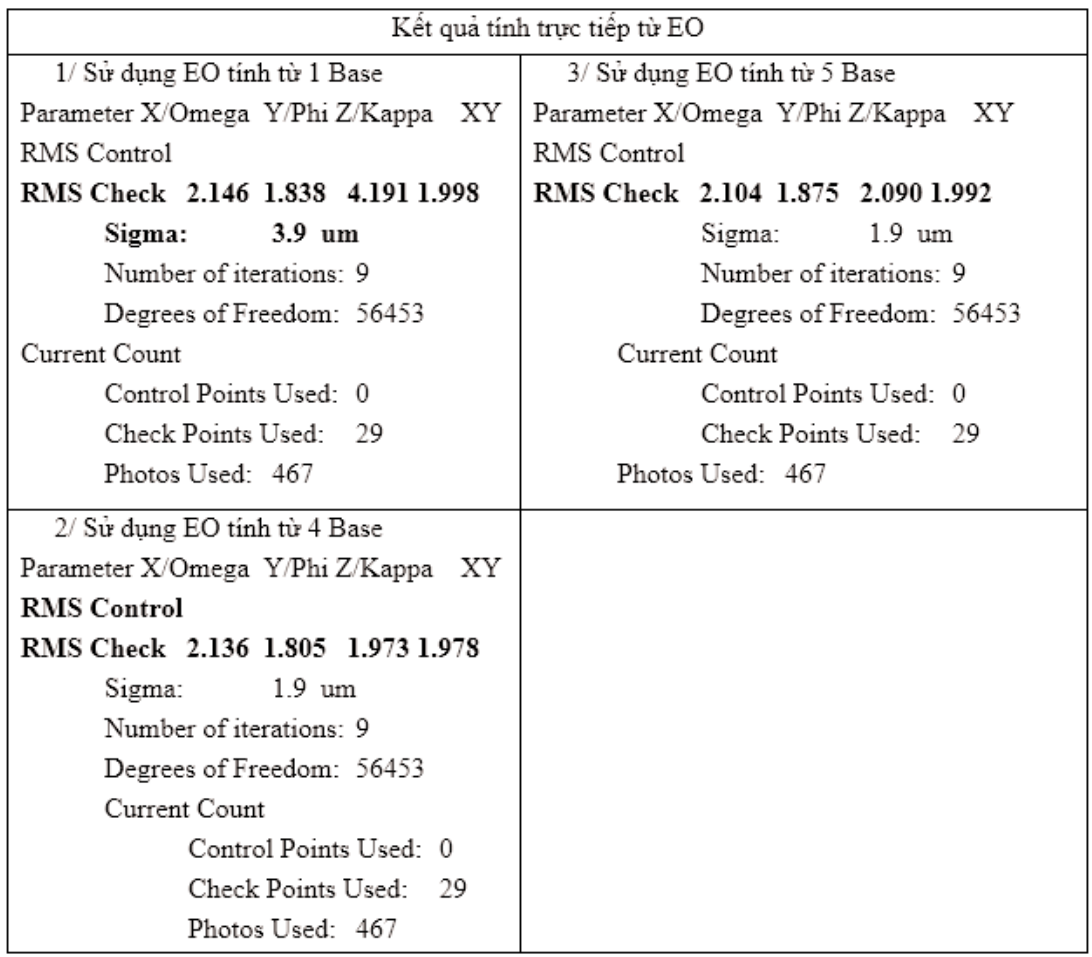


1/ Với các phương án tính toán bình sai tăng dày khống chế ảnh chỉ sử dụng giá trị EO: sai số trung phương tại các điểm kiểm tra về mặt phẳng tương đương nhau, về độ cao với $\mathrm{EO}$ tính từ 4 và 5 trạm Base có độ chính xác tốt hơn $\mathrm{EO}$ tính từ 1 trạm Base (1.973m, 2.090m, 4.191m). Với kết quả như vậy, nếu sử dụng 4 hoặc 5 trạm Base khi bay chụp ảnh,hoàn toàn có thể sử dụng trực tiếp giá trị nguyên tố định hướng ngoài của ảnh trong tính toán tăng dày khống chế ảnh phục vụ thành lập bản đồ địa hình tỷ lệ 1: 10.000, khoảng cao đều đường bình độ cơ bản $10 \mathrm{~m}$.

2/ Nếu chỉ sử dụng cho hiện chỉnh bản đồ địa hình hoặc bản đồ địa chính tỷ lệ 1: 10.000 thì với độ phân giải $50 \mathrm{~cm}$, không cần phải đo khống chế ảnh ngoại nghiệp. $\bigcirc$

\section{Tài liệu tham khảo}

[1]. Báo cáo tổng kết dự án: "Xây dựng co" sở dũ liẹu nền thông tin địa hình co bản và thành lập bản đồ địa hình tỷ lệ 1:50.000 phủ trùm các khu vưc Bắc và Trung Lào”. Cục Đo đạc, Bản đồ và Thông tin địa lý Việt Nam

[2]. POSPac MMS GNSS-Inertial User Guide, Applanix Corporation, 2009

[3]. Hướng dẫn sử dụng phần mềm Image Station. $\bigcirc$

\section{QUY CHIẾU TRỊ ĐO SÂU ĐỊA HÌNH ĐÁY BIỂN.......}

(Tiếp theo trang 23)

\section{Summary}

Referring results of measuring seabed's depth based on sea surface models

Luong Thanh Thach

Hanoi University of Natural Resources and Environment

Nguyen An Dinh

Survey and Aerial mapping onememberLtd. Company

Nguyen Thi Hong

Vietnam Maritime University

Tran Van Hai

Survey Enterprise, Survey and Aerial mapping onememberLtd. Company

This article presents the method of referring the results of measuring seabed's depth based on the regional average sea surface model (MBTBKV98) and the regional lowest sea surface model (MBTNKH170) published in document [6]. The results of assessing the accuracy of the difference between the depths referred based on the average sea surface at a tidal testing station and on model MBTBKV98 in Hai Phong sea area reached $0.018 \mathrm{~m}$, while the difference between the depths referred based on the lowest sea surface at a tidal testing station and based on model MBTNKV170 reached $0.038 \mathrm{~m}$. This shows that the use of sea surface models to refer to topographic depth measurements fully meets the technical requirements prescribed by the Survey and Mapping industry. $O$ 